\title{
CHALLENGES OF THE PRECEPTORS WORKING WITH NEW NURSES: A PHENOMENOLOGICAL RESEARCH STUDY
}

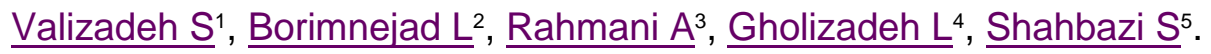

\begin{abstract}
Introduction: Preceptors play an important role in the transition of new nurses to the practice setting, however, preceptorship experience has been perceived as stressful by preceptors. This study aimed to explore the lived experiences of nurse preceptors working with new nurses.

Method: This qualitative study used the hermeneutic phenomenological design to explore the experiences of six nurse preceptors working with new nurses in a tertiary pediatric teaching hospital in Northwest of Iran, who were recruited by purposive sampling. Data were collected using in-depth semi-structured individual interviews between July 2014 and March 2015, and analyzed using the Diekelmann's seven-stage method.

Results: Data analysis revealed three themes: 1) preceptorship as a challenging and stressful role; 2) lack of support; and 3) lack of appreciation. Preceptorship as 'a challenging and stressful role' was the constitutive pattern that unified the themes.

Conclusion: The preceptorship of new nurses is challenging and stressful. Preceptors endure several roles concurrently, thus, their workload should to be balanced appropriately in order not to compromise with one another and evade burnout. The preceptors need to be well supported and their contribution be appropriately recognized. Setting clear objectives and realistic expectations, and having clear policies and guidelines in place should help develop a preceptorship program that is more likely to bring about positive outcomes for both preceptors and new nurses.
\end{abstract}

\section{Keywords:}

Preceptorship, preceptor, new nurses, phenomenological hermeneutics, clinical practice 


\section{INTRODUCTION}

The increasing shortage of nurses on one hand and the demand for high quality care on the other have led to growing pressure on newly graduated nurses to provide effective independent patient care (Wangensteen et al., 2012). However, new nurses are often inadequately prepared to meet the demands of today's complex care environments (Greene, 2010; Monaghan, 2015; Odland et al., 2014; Rush et al., 2013; Yousefy et al., 2015). There is solid evidence that new nurses can benefit from a supported and structured preceptorship during their transition to a professional nurse (Rush et al., 2013; Whitehead et al., 2013). Preceptorship is a formal preplanned relationship between an experienced and new nurse, designed to help the new nurse to adapt to and successfully perform essential job duties (Kalischuk et al., 2013). Preceptorship is based on the assumption that a consistent one-to-one relation between an experienced and new nurse would refresh new nurses training prior to undertaking with patients in a clinical setting. A successful preceptorship program can facilitate adaptation of new nurses to the workforce and helps improve patient safety (Phillips, 2006). Also, if related to the mission and goals of the nursing unit, this role can help with the successful implementation of changes within the unit (Moore, 2008). The program has been found successful in retaining new nurses in the profession (Chen et al., 2011; Goss, 2015), and provided personal and professional growth opportunities for the preceptors (Chen et al., 2011; Muir et al., 2013).

Nevertheless, the role of preceptorship has been referred to in the literature as 'challenging and stressful' (Hautala et al., 2007; Muir et al., 2013), and preceptors often find it difficult to balance their caring and teaching roles without compromising one another. Overall, studies that have focused on the experiences of preceptors are scarce, and the available research has mainly addressed the experiences of preceptors working with undergraduate nursing students (Dodge et al., 2014; Higgins et al., 2010; Muir et al., 2013; Omansky, 2010). The aim of this study is to explore the experiences of preceptors working with new nurses in Iran. This insight is important to help develop effective preceptorship programs that can lead to more positive outcomes for both preceptors and preceptees (Yonge et al., 2008). Although the provision of transitional 
support to new nurses through preceptorship programs is a well-established practice in developed countries (Goss, 2015), this program is increasingly being recognized and implemented in Iran (Negarandeh, 2014). Therefore, there is little known about the process of implementation of this program in Iran. To our best knowledge, there is no study focusing on the experiences of preceptors of working with new nurses in this country.

The Bachelor of Nursing is a 4- year full time program in Iran. All universities that offer this program follow a national teaching curriculum, set up by the Ministry of Health and Medical Education. Upon the successful completion of the program, all students are automatically registered as 'nurse' by the ministry and receive the permission to practice. Yet, similar to findings from other countries, newly graduated nurses in Iran perceive themselves as not being confident to enter the workforce. They report lacking sufficient knowledge and skills required to function as a professional nurse. The nurse preceptorship program is, therefore, intended to help .alleviate these stresses and ease the transition process for new nurses.

\section{METHODS}

This qualitative study employed a hermeneutic phenomenology design based on Heidegger's philosophy to study the individual experiences of preceptors of their preceptorship role and challenges that they encounter. This research design was deemed appropriate as it enabled gaining deeper insights into the individual experiences of the preceptors (Creswell et al., 2007). Data were collected through in depth semi structured individual interviews with the preceptors who were recruited from different wards of a teaching tertiary pediatric hospital in the Northwest of Iran. Inclusion criteria included having Bachelor's or Master's degree in nursing and currently working as preceptor. Participants were within age range of 32 to 46 years, female, and had Bachelor's degree in nursing. They worked as registered nurse between 8 to 18 years, with 12.5 years in average, and were involved in preceptorship of at least 10 new nurses.

The preceptorship program in the hospital, where this study took place, was established approximately four years ago to help smooth the transition of new nurses into their professional role. The program is offered to nurses who are either newly graduated with no previous work experience or experienced nurses who are new to the hospital. The preceptorship period is limited to 2-4 weeks, during which the new nurse works under the supervision of a preceptor. 
The preceptor is an experienced nurse who is often nominated by the nurse unit manager and appointed to the role by the director of nursing. The preceptor is responsible for training of the new nurse on ward specific procedures and ensuring their safe practice. There is no formal training for the preceptorship role in Iran. The Preceptor may request to resign from their role, although it rarely occurs. In that case, the director of nursing may convince the preceptor to continue on their role. However, if the preceptor has a legitimate reason/s, their resignation is accepted.

The study received ethical approval from the ethics committee of Tabriz University of Medical Sciences (ethics code: 5.4.46.12). Participants were provided with both verbal and written information about the study and gave informed consent to the study. All potential participants, who were invited to share their preceptorship experiences with the researchers in an in-depth semi-structured individual interview, accepted the invitations. Interviews were carried out between July 2014 and March 2015. We asked the participants to talk about their experiences of working with new nurses and the challenges they faced. Probing questions were asked if clarification or additional information was desired. All the interviews were carried out in Persian language by one of the researchers (Sh Sh). Participants knew the interviewer from her previous position as the educational supervisor of the participating hospital, however, at the time of the interviews, the interviewer was no longer working in the hospital. This was acknowledged as a source of bias by the researchers and to minimize this bias, the participants were reassured of the confidentiality of any given information. Their confidentiality was also protected by keeping the signed consent forms separate from the transcripts and using pseudonyms.

The venue for the interviews was mutually agreed upon and five out of the six participants suggested that the interviews to be carried out in the hospital where they worked. The interviews were conducted in a quiet room, lasted between 22 to 63 minutes, and audio recorded. At the end of each interview, the interviewer confirmed with the participant that their understanding of the participant's views and experiences was complete and accurate.

\section{Data analysis}

All the interview data were transcribed verbatim, and the transcriptions were analyzed using the seven stage method described by Diekelmann et al. (Diekelmann et al., 1989). Data analysis 
started immediately after the first interview. In the first stage of the analysis, the transcript of each interview was read by one of the authors to obtain an overall understanding. An interpretive summary of each interview was written in the second stage. The transcriptions were then imported into MAXQDA10 software for data coding and analysis (Kuckartz and Kuckartz, 2002), leading to identification of preliminary themes. The findings of the preliminary analysis were discussed within the research team. The analysis of each interview determined whether the subsequent interview to be carried out with the same participant or a new participant. To ensure the richness and depth of data, some participants were interviewed more than once (Morse, 2000). The follow up interviews also helped clarify uncertainties and any disagreement within the research team on interpretation of the preceptors' experiences. Interviews were carried out with 6 preceptors; as some preceptors were interviewed more than once, this boosted up the total number of the interviews to 11 interviews. Data saturation was achieved after interview with the $5^{\text {th }}$ preceptor, however, one further participant was interviewed to ensure the saturation. Comparing and contrasting all the transcripts led to identification and description of shared practices and common meanings among the preceptors. Relational themes were identified, and the constitutive pattern linking the relational themes was emerged through comparing and contrasting the themes. Lastly, the relational themes and the constitutive pattern were discussed within the research team.

\section{FINDINGS}

Analysis of the interview data yielded three themes and a constitutive pattern of 'preceptorship as challenging and stressful', representing the highest relational pattern of all the themes. The study themes included: 1) preceptorship a challenging and stressful role 2) lack of support 3), and lack of appreciation.

\section{1) Preceptorship as a challenging and stressful role}

The participants found the role of preceptorship as challenging and stressful. They believed that a quality preceptorship required considerable time and efforts. In addition to training and supervising of new nurses, the preceptors were also expected to act as a good role model and provide their patients with a higher quality care, and because of their work experience and expertise they were assigned to critically ill patients and worked as the nurse in charge. 
Sometimes, a new nurse was replaced an experienced nurse due staff storages, while they were expected to work under supervision of the preceptor. In these circumstances, the preceptors were not only expected to take the responsibilities of their own patients as a bedside nurse, but also patients whom were taken care of by the new nurse. The participants exclaimed that due to the poor nurse to patient ratio, their workload was already stretched. These conditions added to their workload, mounting job pressure and stress. Taking on multiple roles within a single working shift including preceptorship, nurse in charge, bedside nurse, as well as nursing of critically ill patients was perceived by the preceptors as extremely challenging and stressful.

"... sometimes we also are assigned as the nurse in charge. As the preceptor, you are under a lot of pressure. Patients are allocated equally between nurses including the preceptor. Sometimes the preceptor takes responsibility of critically ill patients too, as less experienced nurses can't look after them. So, at the end of the day, I would say why I should bear a greater work pressure than others?" (Participant 4)

Preceptors found handling their clinical tasks easier when they worked as a bedside nurse alone, as they could apply strategies that they had learnt from previous experience. However, when paired up with a new nurse, they had to explain every detail of the work, which took considerable amount of the preceptors' time, leading to late hour work and exhaustion.

"... When I work with her (new nurse), I have to explain every single thing. This takes a lot of my time. Sometimes, I have to leave the work at 3:30 pm, or around 9:30pm if it is an evening shift, which is too late in winter... I tolerate these things anyway." (Participant 2)

Preceptors stated that at times they had to compromise on some of their responsibilities due to the excessive workload. However, patients were always given the top priority, and in intense working situations, the preceptorship role was more likely to be compromised, leading to feelings of guilt and self-criticism in the preceptors.

“... I have my own patients. I can't compromise on them. Morning shifts are, particularly, very busy. I feel like my main responsibility is to look after my patients rather training a new nurse. In these circumstances, I prefer to attend to my patients' needs" (participant 5) 
"... I want to be the best for my patient; at the same time, I know that someone needs to learn from me. It feels really bad when I can't attend their needs. It is too hard to bear this tension. That's why I no longer want to be a preceptor." (Participant 5)

The preceptors critiqued the preceptorship role for being too ambiguous and inconsistent. They believed that the preceptorship program should be based upon predetermined and transparent goals and objectives.

“... If we want it (the preceptorship program) to work, it should be carefully planned, expectations should be made clear. These things should be clear, so preceptors know what they should be doing." (Participant 4)

The lack of clear goals, objectives, and guidelines on one hand and allocation of new nurses to different preceptors on the other resulted in inconsistent preceptorship as well as uncertainty and confusion among the preceptors and new nurses. Participants exclaimed that they often worked in isolation and believed networking opportunities should be created so that the preceptors could share their experiences. Participants also believed that educational supervisors should be effectively involved in the preceptorship program, providing the preceptors with educational support and resources.

"They (educational supervisors) should hold meetings for the preceptors, like once every a few months; so, the preceptors have the chance to talk about the challenges that they face." (Participant 4)

\section{Lack of support}

The preceptors stated that they started their role with a poor knowledge base and low confidence. They were appointed as 'the preceptor' by the nursing service administrator of the participating hospital without a prior consultation or a notice. As the result, the preceptors were not wellprepared to take on the preceptorship role mentally and educationally, leading to the experience of significant distress during the early stages of their preceptorship role.

"... It was out of the blue and I had not received any notice. ... without any background or training." (Participant 4) 
"... They should offer us some courses, so that the preceptors are well prepared for the role, and they can give more consistent training to new nurses. Training can also help us be more capable and in terms of knowledge be superior to new nurses." (Participant 1)

The preceptors also expressed their dissatisfaction with the allocation of new nurses to different preceptors. They believed that a new nurse should be assigned to the same preceptor for the whole period of the preceptorship to allow for more consistent training.

"...We (the preceptors and new nurses) are sometimes allocated to different working shifts. We (the preceptors) have to work in rotating shifts: mornings, afternoons, and night shifts, while new nurses only do the morning shifts. It is unusual that we are allocated to the same shifts as new nurses for three or four shifts in a row, unless they (new nurses) are very lucky." (Participant 2)

The inconsistency in the training was perceived as a barrier, impeding preceptors from effectively assessing the educational needs of new nurses and providing them with timely and constructive feedback. Also, the lack of coordination in the working shifts of the preceptors and new nurses resulted in the preceptors feeling hopelessness and having a sense that their contribution to the training of new nurses was not important to authorities.

"... I want to continue on my teaching, but I'm not working with the nurse on the following shift. So, I am not sure if she really got what I taught her. I have to wait and find it out sometime in the next a few days, when we are both working on the same shift." (Participant 6)

Participants critiqued the health care system for not providing the preceptors with adequate support. They expressed that authorities including nursing service unit, supervisors and head nurses did not provide sufficient support to the preceptorship program. They believed that the support of the preceptors in the form of reduction in workload could release the preceptors' time to spend more time with new nurses.

“... unfortunately, the managers don't care much about new nurses. Otherwise, they would create a situation where the appointed preceptors would feel comfortable, so they could better assist new nurses." (Participant 4) 
The preceptors also did not receive support from nurses working on the floor. The bedside nurses considered the training of new nurses to be the responsibility of the preceptors only and they were reluctant to share their experiences with new nurses or provide supporting hands to the preceptors.

“... no one wants to really get involved. At least, they could, for example, say like my patient is an interesting case, she (new nurse) can come and learn about, or that there is something worth learning. No, nothing like that... if someone asks something from them directly, they would answer, otherwise nothing... The only one working with the new nurse is the preceptor." (Participant 6)

\section{Lack of appreciation}

The preceptors critiqued the system for not adequately appreciating their contribution and believed that authorities were not aware of the hidden work involved in the preceptorship. They did not receive any benefit or bonus in return for their preceptorship services. The preceptors expected rewards in the form of financial incentives, workload reduction, or that their personal roster preferences are taken into account. They exclaimed that all they received in return for their hard work was a certificate of appreciation, which was not perceived as sufficient by the preceptors.

“... as a preceptor, I'd like my preferences to be taken into consideration when scheduling my shifts, but it doesn't happen." (Participant 5)

"There is no financial bonus; I have been given appreciation letters...twice a year and then once a year." (Participant 2)

Although internal motivation was mentioned as the most influential factor in taking on the preceptorship role, lack of external incentives led to disappointment and dissatisfaction in the preceptors.

“... that's why I don't like this job. If you've appointed me as a preceptor, I should get some benefits in return. I do extra work as a preceptor. What benefit do I get? Do I get paid for after hour work? Or am I given extra privileges? No, nothing. I get reprimanded when I don't do the job properly, but if I do it properly, it is part of my duty!!” (Participant 4) 
The preceptors were deemed responsible for errors made by new nurses and they were frequently critiqued and reprimanded by authorities and colleagues for the shortcomings. This was perceived as extremely distressing and unjust by the preceptors considering the fact that they were not trained for the preceptorship role or provided with adequate support. Likewise, the preceptors believed that the preceptorship program was too short and did not provide the new nurses with adequate opportunities to practice and master some of skills they learnt during the preceptorship period.

"... the stress was too high, if the nurse did not know something, you would be accused of not properly training them. We would be threatened of getting lower rates in the staff performance evaluation. I would rather help out a new nurse as a colleague than work with her as a preceptor, just because of these penalties." (Participant 2)

Being criticized in front of other colleagues had such tremendous effects that some of the preceptors even considered stepping down from their role.

"... once I didn't get the chance to teach a new nurse, the ward was too crowded and my patients were critically ill. I had to ask her (nurse) to just observe my work. At the handover, in front of everyone, the head nurse said: "why didn't you teach her?" These kinds of reprimands were very distressing. At times, I even decided to give it up because of these reprimands and humiliations in front of new nurses and other colleagues, but then I changed my mind." (Participant 4)

\section{DISCUSSION}

The findings of this study provide insights into the experiences of the preceptors during the preceptorship of new nurses. Overall, participants in this study perceived the role of preceptorship as being challenging, leading to a great deal of stress. These adverse experiences appear to be common among the preceptors across different settings and countries (Chen et al., 2011; Liu et al., 2010; Panzavecchia and Pearce, 2014; Richards and Bowles, 2012). The preceptors, in the current study, were appointed to the role with no consultation or prior notice. This resulted in the preceptors experiencing significant amount of stress in the early stages of their work as preceptor. They stepped into the role with low confidence and were not mentally and educationally prepared to take on the preceptorship role. The preceptors believed that 
delivering an effective preceptorship required appropriate training and preparation. Consistent with this finding, preceptors, in a recent UK study, reported inadequate training as a barrier to successful preceptorship (Whitehead et al., 2016). There is often an assumption that nurses who are appointed as 'preceptor' are experienced and possess the necessary skills for the role (Bengtsson and Carlson, 2015). However, the results of this study and other studies suggest that successful preceptorship is highly contingent upon the skills of the preceptors and the preceptors should receive some formal training in preparation for their role (Chang et al., 2015; Rush et al., 2013; Whitehead et al., 2016).

Other major factors deterring effective preceptorship included excessive workload, working in isolation, lack of adequate support, lack of appreciation and role ambiguity (Hautala et al., 2007; Watson et al., 2012). The preceptors were assigned to the same number of patients as other nurses on the floor. In addition, due to their expertise and experience, the preceptors were expected to take care of critically ill patients and work as the person in charge. These responsibilities were often to be endured simultaneously, resulting in significant work related stress. Excessive workload has been identified in the literature as a barrier to effective preceptorship (Richards and Bowles, 2012). In intense working situations, the preceptorship role was more likely to be compromised. Although the preceptors expressed that at any circumstances they would give the higher priority to patients, a compromise to the preceptorship role can potentially compromise patient safety. Similar to our finding, the preceptors in a hospital in Ireland emphasized that in extreme workload situations they would not compromise on their patients' care needs (McCarthy and Murphy, 2010). However, the preceptors in Taiwan expressed that they would give the higher priority to their preceptorship role (Chen et al., 2011). Individual values and attitudes and the values espoused by the organization may affect the way preceptors prioritize their various roles. The findings of this study and other studies suggest that failure to contribute positively to the preceptorship role can result in the preceptors experiencing negative feelings, such as guilt and self-criticism (Chen et al., 2011; McCarthy and Murphy, 2010).

The preceptors in this study described their experience of working with new nurses as 'being left alone', with no adequate support from nurse managers and bedside nurses. They felt that the workload involved in the preceptorship role was often underestimated and new nurses were 
assumed as full working forces. On the hand, the preceptors were critiqued for shortcomings and errors caused by new nurses, findings that are also supported by other studies (Chang et al., 2015; Panzavecchia and Pearce, 2014; Whitehead et al., 2016). The literature is mixed regarding the level of organizational support provided to the preceptors. In Bourbonnais and Kerr study (2007), the preceptors, who were involved in the preceptorship of nurse students in their final clinical placement in a Canadian hospital, reported that they received insufficient managerial support during the preceptorship program (Bourbonnais and Kerr, 2007). However, a study in the USA reported that the preceptors were mainly satisfied with the level of support that they received from managers (Hautala et al., 2007). Managers can support the preceptors by balancing their workload, providing free access to educational resources, and offering an array of professional development opportunities such as, leadership, prioritization skills, time management and effective delegation skills. Managers can also support the preceptorship program through coordinating the working shifts of the preceptors and preceptees, a factor that is overlooked by authorities (Luhanga et al., 2010). For consistency in the training, it also is important that preceptorship is based on a one-to-one relation (Luhanga et al., 2010). Networking opportunities should be created for the preceptors to discuss and exchange ideas with other preceptors. This is likely to result in more positive experiences and improved job satisfaction for the preceptors (Blozen, 2010; Goss, 2015; Sandau et al., 2011).

Unlike the preceptorship programs for nursing students, which are generally supported by the faculty, new graduate nurse programs receive support from the educational supervisor of the hospital (Myrick and Yonge, 2005). In the setting of this study, educational supervisor is someone who acts as an intermediary between nursing service manager, the preceptor and new nurse, and is responsible for developing, monitoring, retaining, and evaluating the quality of the new nurse preceptorship program. The educational supervisor is accountable for training, support and assessment of the preceptors and new nurses during the entire preceptorship training. However, participants in the current study believed that they did not receive adequate support from authorities including the educational supervisor, a finding that has also been identified in the literature (Bourbonnais and Kerr, 2007). The preceptors were also dissatisfied with the lack of support from bedside nurses. This finding is also mainly in line with prior studies (Bourbonnais and Kerr, 2007; Chen et al., 2011; Liu et al., 2010), although in Hautala et al.'s 
(2007), the preceptors were overall satisfied with the level of support they received from colleagues (Hautala et al., 2007). Lack of awareness of the objectives of the preceptorship program, misunderstanding the need for and the importance of collaboration of all staff, or heavy workload may be some barriers to an effective collaboration of bedside nurses with the program and these factors should be investigated in future research. A supportive and fostering environment is needed to overcome the known barriers and achieve high quality preceptorship program. This should increase the satisfaction of both new nurses and the preceptors of the program and lead to growth and job retention (Chen et al., 2011).

The preceptors in this study made many sacrifices such as bearing intense workloads, taking on multiple roles and working late hours, yet, their contribution was not satisfactorily recognized. Although the preceptors received letters from mangers in appreciation of their contribution to the program, it was not perceived as adequate. The preceptors favored some kind of financial support, workload reduction or having their work preferences taken into account. Inadequate appreciation of the preceptors' contribution and lack of an appropriate external reward system have been found to adversely affect the satisfaction of the preceptors of their role (Goss, 2015; Hautala et al., 2007). Being reprimanded in front of colleagues was found as extremely embarrassing, humiliating, disheartening, and demoralizing by the preceptors and a factor that significantly affected their satisfaction of the role. This finding seems to be unique to this study and the reprimand of the preceptors in front of other colleagues has not been explicitly pointed out in the literature (Chang et al., 2015).

The findings of this study and other research suggest that lack of clear objectives, expectations, and guidelines hinder effective preceptorship (Enrico, 2011; Madhavanpraphakaran et al., 2014; Marks-Maran et al., 2013; Muir et al., 2013). The preceptorship program should be based on clear goals and expectations to avoid role confusion (Alonaizi and Paliadelis, 2015). The program should bring about benefits for new nurses, the preceptors, patients and organizations, however, lack of shared objectives may result in unrealistic expectations and outcomes (Paterniti 2006).

Preceptorship policies and guidelines need to be developed and implemented at local and national levels to inform the programs. This should include developing clear selection criteria, 
learning objectives and roles and responsibilities as well as the ways in which the preceptors can be supported and their contribution recognized (Goss, 2015).

\section{Limitations}

This is a single center study involving female participants only. Hence, the findings may not reflect the experiences of male preceptors or the preceptors working with new nurses in other hospitals. Barriers to the preceptorship program need to be further investigated from the perspectives of the preceptors, new nurses, beside nurses and mangers and factors affecting the program outcomes, such as role satisfaction and staff retention be identified.

\section{CONCLUSIONS}

The preceptors who work with new nurses face many challenges. To enhance the program outcomes, it is important that the preceptors are supported throughout the proctorship program, their perspectives are taken into account, a sound workload is expected, and the preceptors' contribution is appropriately recognized. Setting clear objectives, expectations, and guidelines can help design and deliver a preceptorship program which is likely to bring about more consistent, standardized training and positive outcomes for both preceptors and new nurses. 


\section{REFERENCES}

Alonaizi, N., Paliadelis, P., 2015. Triple Ps and Cs to solve the trouble of transition: A new theoretical model. Journal of Health Specialties 3, 216-223.

Bengtsson, M., Carlson, E., 2015. Knowledge and skills needed to improve as preceptor: development of a continuous professional development course-a qualitative study part I. BMC Nursing 14, 51.

Blozen, B., 2010. Avoiding preceptor burnout. American Nurse Today 5, 41-42.

Bourbonnais, F.F., Kerr, E., 2007. Preceptoring a student in the final clinical placement: reflections from nurses in a Canadian Hospital. Journal of Clinical Nursing 16, 1543-1549.

Chang, C.-C., Lin, L.-M., Chen, I.-H., Kang, C.-M., Chang, W.-Y., 2015. Perceptions and experiences of nurse preceptors regarding their training courses: A mixed method study. Nurse education today 35, 220-226.

Chen, Y.-H., Duh, Y.-J., Feng, Y.-F., Huang, Y.-P., 2011. Preceptors' experiences training new graduate nurses: a hermeneutic phenomenological approach. Journal of Nursing Research 19, 132-140.

Creswell, J.W., Hanson, W.E., Plano, V.L.C., Morales, A., 2007. Qualitative research designs selection and implementation. The counseling psychologist 35, 236-264.

Diekelmann, N., Allen, D., Tanner, C., 1989. The NLN criteria of appraisal of baccalaureate programs: a critical hermeneutic analysis. New York: National League for Nursing Press.

Dodge, T., Mazerolle, S.M., Bowman, T.G., 2014. Challenges faced by preceptors serving in dual roles as health care providers and clinical educators. Athletic Training Education Journal 9, 29-35.

Enrico, N.B., 2011. The Lived Experiences of Mentoring Nurses in Malaysia. Nurse Media Journal of Nursing 1, 87-104.

Goss, C.R., 2015. Systematic Review Building a Preceptor Support System. Journal for nurses in professional development 33, E7-E14.

Greene, M.A., 2010. Paying for Nursing Orientation: A Huge Cost to Hospitals. Journal for Nurses in Staff Development 26, E3-E7.

Hautala, K.T., Saylor, C.R., O'Leary-Kelley, C., 2007. Nurses' perceptions of stress and support in the preceptor role. Journal for Nurses in Staff Development 23, 64-70.

Higgins, G., Spencer, R.L., Kane, R., 2010. A systematic review of the experiences and perceptions of the newly qualified nurse in the United Kingdom. Nurse Education Today 30, 499-508.

Kalischuk, R.G., Vandenberg, H., Awosoga, O., 2013. Nursing Preceptors Speak Out: An Empirical Study. Journal of Professional Nursing 29, 30-38.

Khomeiran, R.T., Deans, C., 2007. Nursing education in Iran: Past, present, and future. Nurse education today 27, 708-714.

Kuckartz, A.M., Kuckartz, U., 2002. Qualitative text analysis with Maxqda. Fundación Centro de Estudios Andaluces, pp. 1-29.

Liu, M., Lei, Y., Mingxia, Z., Haobin, Y., 2010. Lived experiences of clinical preceptors: A

phenomenological study. Nurse education today 30, 804-808.

Luhanga, F.L., Billay, D., Grundy, Q., Myrick, F., Yonge, O., 2010. The one-to-one relationship: is it really

key to an effective preceptorship experience? A review of the literature. International Journal of Nursing Education Scholarship 7, Article21.

Madhavanpraphakaran, G.K., Shukri, R.K., Balachandran, S., 2014. Preceptors' Perceptions of Clinical Nursing Education. J Contin Educ Nurs 45, 28-34.

Marks-Maran, D., Ooms, A., Tapping, J., Muir, J., Phillips, S., Burke, L., 2013. A preceptorship programme for newly qualified nurses: A study of preceptees' perceptions. Nurse education today 33, 1428-1434.

McCarthy, B., Murphy, S., 2010. Preceptors' experiences of clinically educating and assessing undergraduate nursing students: an Irish context. Journal of Nursing Management 18, 234-244. 
Monaghan, T., 2015. A critical analysis of the literature and theoretical perspectives on theory-practice gap amongst newly qualified nurses within the United Kingdom. Nurse education today 35, e1-e7.

Moore, M.L., 2008. Preceptorships: hidden benefits to the organization. Journal for Nurses in Professional Development 24, E9-E15.

Morse, J.M., 2000. Determining sample size. Qual. Health Res. 10, 3-5.

Muir, J., Ooms, A., Tapping, J., Marks-Maran, D., Phillips, S., Burke, L., 2013. Preceptors' perceptions of a preceptorship programme for newly qualified nurses. Nurse education today 33, 633-638.

Myrick, F., Yonge, O., 2005. Nursing preceptorship: Connecting practice and education, 1st ed. Lippincott Williams \& Wilkins, Philadelphia.

Negarandeh, R., 2014. Enhancing Transition to Workplace. Nursing and Midwifery Studies 3, e17554.

Odland, L.-H., Sneltvedt, T., Sörlie, V., 2014. Responsible but unprepared: Experiences of newly educated nurses in hospital care. Nurse education in practice 14, 538-543.

Omansky, G.L., 2010. Staff nurses' experiences as preceptors and mentors: an integrative review. Journal of nursing management 18, 697-703.

Panzavecchia, L., Pearce, R., 2014. Are preceptors adequately prepared for their role in supporting newly qualified staff? Nurse education today 34, 1119-1124.

Phillips, J.M., 2006. Preparing preceptors through online education. Journal for Nurses in Professional Development 22, 150-156.

Richards, J., Bowles, C., 2012. The meaning of being a primary nurse preceptor for newly graduated nurses. Journal for Nurses in Professional Development 28, 208-213.

Rush, K.L., Adamack, M., Gordon, J., Lilly, M., Janke, R., 2013. Best practices of formal new graduate nurse transition programs: an integrative review. International journal of nursing studies 50, 345-356.

Sandau, K.E., Cheng, L.G., Pan, Z., Gaillard, P.R., Hammer, L., 2011. Effect of a preceptor education workshop: part 1. Quantitative results of a hospital-wide study. Journal of continuing education in nursing 42, 117-126.

Wangensteen, S., Johansson, I.S., Bjorkstrom, M.E., Nordstrom, G., 2012. Newly graduated nurses' perception of competence and possible predictors: a cross-sectional survey. Journal of professional nursing : official journal of the American Association of Colleges of Nursing 28, 170-181.

Watson, L.C., Raffin-Bouchal, S., Melnick, A., Whyte, D., 2012. Designing and implementing an ambulatory oncology nursing peer preceptorship program: Using grounded theory research to guide program development. Nursing research and practice 2012.

Whitehead, B., Owen, P., Henshaw, L., Beddingham, E., Simmons, M., 2016. Supporting newly qualified nurse transition: A case study in a UK hospital. Nurse education today 36, 58-63.

Whitehead, B., Owen, P., Holmes, D., Beddingham, E., Simmons, M., Henshaw, L., Barton, M., Walker, C., 2013. Supporting newly qualified nurses in the UK: A systematic literature review. Nurse education today 33, 370-377.

Yonge, O., Hagler, P., Cox, C., Drefs, S., 2008. Listening to preceptors: Part B. Journal for Nurses in Professional Development 24, 21-26.

Yousefy, A., reza Yazdannik, A., Mohammadi, S., 2015. Exploring the environment of clinical baccalaureate nursing students' education in Iran; A qualitative descriptive study. Nurse education today 35, 1295-1300. 